\title{
Para uma abordagem sócio-histórica da relação entre as noções de gênero do discurso e de tipo do discurso
}

\author{
Gustavo Ximenes Cunha ${ }^{a}$
}

\begin{abstract}
Resumo
Este trabalho apresenta uma abordagem para o estudo da relação entre gêneros do discurso e tipos do discurso. A abordagem parte da hipótese de que essas noções são de tal modo imbricadas que cada gênero possui tipos específicos. Para verificar a validade $e$ o alcance dessa hipótese, este trabalho procura, inicialmente, fornecer evidências de que as teorias que concebem os tipos e as sequências como esquemas (linguísticos ou referenciais) universais não resistem à análise de uma sequência narrativa simples. Após evidenciar a inconsistência dessas teorias, proponho, em seguida, a abordagem mencionada, que tem como objetivos contornar os problemas inerentes a elas $e$ permitir elucidar aspectos ainda desconhecidos do funcionamento dos gêneros e do modo como deles nos valemos para alcançar fins específicos.
\end{abstract}

Palavras-chave: tipos de discurso; gêneros do discurso; abordagem discursiva. 


\section{Introdução}

Este trabalho tem sua origem na percepção do que considero um problema de natureza teórica para os estudos da linguagem que se preocupam com o modo como os interactantes elaboram e interpretam produções discursivas. Esse problema diz respeito à hipótese relativamente consensual de que os gêneros (textuais/discursivos) são formas relativamente estáveis de enunciados sócio-historicamente constituídos, ao passo que os tipos (textuais/discursivos) são sequências textuais com características bem definidas, que entram na composição de exemplares de todos os gêneros.

Ainda segundo essa hipótese, os gêneros são concebidos como entidades que surgem e se constituem atreladas às necessidades históricas e sociais e que, por isso, dizem respeito a "formas culturais e cognitivas de ação social corporificadas de modo particular na linguagem" (MARCUSCHI, 2008, p. 156). Já os tipos, por serem concebidos como sequências com características linguísticas e referenciais típicas e bem conhecidas, dizem respeito a entidades universais e pouco dinâmicas, que, por isso mesmo, apresentariam, em maior ou em menor grau, as mesmas propriedades em quaisquer produções discursivas.

Como decorrência dessa hipótese geral, defende-se que os gêneros são variados e quase infinitos (notícia, poema, romance, canção, bula de remédio, ata de condomínio, entrevista, reportagem, debate, etc), enquanto os tipos se limitam a meia dúzia de categorias (narração, descrição, argumentação, explicação, diálogo, injunção) (ADAM, 1992, BRONCKART, 2007, MARCUSCHI, 2008).

Essa forma de encarar a problemática da relação entre os gêneros e os tipos tem feito com que, nas abordagens para as quais essas noções são relevantes, os tipos, de modo geral, sejam vistos como se fossem menos complexos do que os gêneros, de cuja composição, paradoxalmente, participam. Para essas abordagens, um mesmo tipo narrativo, por exemplo, entraria na composição de todos os gêneros em que se realiza a ação de narrar, em uma perspectiva bem próxima da de Adam (1992, p. 12-13):

A estrutura elementar da sequência narrativa se encontra na base da epopeia, da fábula, da maior parte dos romances, 
das narrações teatrais clássicas de exposição ou de desenlace, mas igualmente da reportagem e do fait divers jornalístico, da narração oral ou da anedota cotidiana.

Por esse motivo, essas abordagens não oferecem uma explicação satisfatória das diferenças profundas que se podem notar no modo como os interactantes narram, descrevem e argumentam ao construírem produções discursivas pertencentes a diferentes gêneros.

Afinal, não se narra da mesma forma em um conto, em uma entrevista de emprego e em um boletim de ocorrência. Da mesma forma, o modo como os jornalistas narram nas notícias de hoje é diferente do modo como os jornalistas narravam nas notícias do início do século XX (PESSOA, 2007). E essas diferenças não parecem se dever à vontade do produtor do discurso de elaborar uma sequência mais ou menos semelhante a um (protó)tipo narrativo universalmente compartilhado, mas antes a um processo sócio-histórico que leva o agente a saber que há maneiras típicas de narrar em cada gênero.

Assim considerada, a hipótese da dicotomia entre gênero e tipo ou da transversalidade dos tipos em relação aos gêneros (SCHNEUWLY, 2004) é problemática para os estudos da linguagem, porque deixa sem respostas satisfatórias pelo menos duas questões importantes para a compreensão do modo como elaboramos e interpretamos produções discursivas:

- qual é o modo típico de narrar, descrever, argumentar em dado gênero?

- como um dado gênero contribui para a constituição do modo típico de narrar, descrever, argumentar nesse gênero?

De modo geral, essas questões não fazem parte do rol de questões a serem respondidas pela maior parte das abordagens atuais do texto e do discurso. Afinal, se o tipo é uma entidade descontextualizada e transversal em relação a todos os gêneros, não haveria um modo de narrar, descrever, argumentar característico ou típico de um dado gênero, mas apenas um modo geral e universal de narrar, descrever, argumentar, o qual seria comum a todos os gêneros, exatamente por ser independente de determinações genéricas (sociais, históricas, culturais). 
Posicionando-se contra a hipótese da universalidade e atemporalidade dos tipos ou da transversalidade dos tipos em relação aos gêneros, este trabalho levanta outra hipótese, segundo a qual as noções de gênero e de tipo são de tal forma imbricadas que cada gênero possui tipos específicos. Em outros termos, cada gênero se caracteriza por um modo típico de narrar, descrever, argumentar, etc, o que leva a compreender a noção de tipo como subordinada à de gênero. Nessa perspectiva, o modo típico de narrar do gênero reportagem seria diferente do modo típico de narrar do gênero conto. Da mesma forma, o modo típico de argumentar do gênero artigo científico seria diferente do modo típico de argumentar do gênero bate-papo.

Neste artigo, proponho uma abordagem que se guie pela hipótese aqui defendida, de que as noções de gênero e de tipo são de tal forma entrincheiradas que cada gênero possui tipos particulares. A exposição dessa abordagem recupera, aprofundando, parte da pesquisa desenvolvida em Cunha (2013).

\section{Uma proposta para o estudo da imbricação das noções de gêneros e de tipos}

Nesta abordagem, o tipo de discurso diz respeito a uma representação referencial típica que se constitui em função do gênero do discurso em que é mobilizado. Em outros termos, os tipos são recursos referenciais típicos subordinados a um

"Da mesma maneira que o protótipo do pássaro - geralmente mais próximo do pardal ou do canário - permite distinguir uma coruja, uma cegonha ou mesmo um avestruz e um pinguim de outros animais, parece existir um esquema prototípico da sequência narrativa que permite distingui-la de uma sequência descritiva, argumentativa ou outra. E o esquema ou imagem mental do protótipo-objeto abstrato, construído a partir de propriedades típicas da categoria, que permite $o$ reconhecimento ulterior deste ou daquele exemplo como mais ou menos prototípico" (ADAM, 1992, p. 30-31). gênero, recursos que os agentes selecionam para produzir e interpretar sequências componentes de exemplares desse gênero. Assim, os tipos de discurso (narração, argumentação, descrição) devem ser vistos como recursos referenciais ligados a um dado gênero e não como entidades prototípicas capazes de ser mobilizadas na produção e na interpretação de exemplares de quaisquer gêneros.

Influenciados em especial pela proposta de Adam (1992, 2011), muitos trabalhos acerca da estrutura composicional dos gêneros adotam uma concepção dos tipos de discurso como protótipos. Na proposta desse autor, as diferenças que caracterizam, por exemplo, as sequências narrativas de gêneros diversos podem ser explicadas apenas em termos de graus de semelhança com o protótipo narrativo abstrato e universal ${ }^{1}$.

Porém, é intuitivamente difícil admitir que o jornalista que narra os acontecimentos de uma guerra, o romancista que 
narra uma história fictícia e o radialista que narra uma partida de futebol mobilizem exatamente o mesmo recurso psicológico, que seria o tipo narrativo ou o protótipo da sequência narrativa. As especificidades dessas narrativas sugerem que cada gênero opera uma seleção ou uma especificação dos recursos referenciais, dos quais fazem parte os tipos de discurso.

No gênero reportagem, o tipo narrativo, por exemplo, seria uma representação sobre as propriedades referenciais típicas da narrativa desse gênero e não de quaisquer gêneros. Mais especificamente, seria uma representação sobre a forma como os jornalistas tipicamente constroem a cadeia de acontecimentos (estados e ações) nas sequências narrativas de reportagens, em função das propriedades do gênero reportagem. Dessa forma, definir os tipos de discurso de um gênero implica o estudo do gênero e não apenas dos tipos.

Nessa perspectiva, do ponto de vista metodológico, um analista que, por exemplo, estude sequências descritivas do gênero resenha não deve tomar como ponto de partida de suas análises o tipo descritivo universal, aquele que, conforme a hipótese contra a qual me posiciono, seria subjacente às sequências descritivas pertencentes a exemplares de quaisquer gêneros.

Ao contrário, a hipótese de que cada gênero possui tipos específicos obriga o analista a começar o estudo exatamente pela caracterização do gênero resenha, para depois, em etapa posterior, apreender o modo como tipicamente se descreve nesse gênero e em função do mesmo. Só uma análise como essa, que busque caracterizar os tipos a partir dos gêneros, permite identificar o tipo descritivo da resenha, o qual, segundo a hipótese levantada, seria diferente dos tipos descritivos do poema, do sermão, da receita culinária, do guia turístico, do parecer técnico, etc. Isso porque, como os tipos não são universais e atemporais, mas são tão sócio-historicamente determinados quanto os gêneros que constituem, conhecer o tipo narrativo ou descritivo de um gênero não implica conhecer o tipo narrativo ou descritivo de outro gênero.

A seguir, apresento uma caracterização dos instrumentos de análise desta abordagem e de como eles podem ser empregados no estudo de um tipo de discurso de um gênero específico: o tipo narrativo da reportagem. Com base no método esboçado anteriormente, a abordagem propõe que a análise se faça em três etapas. Na primeira, estuda-se o gênero do discurso cujos 
tipos serão caracterizados. Na etapa seguinte, investiga-se o impacto desse gênero sobre a constituição dos tipos, a fim de descobrir a maneira como nesse gênero tipicamente se narra, descreve ou argumenta. Na terceira etapa, os tipos elaborados na etapa anterior são empregados na identificação de sequências discursivas extraídas de exemplares do mesmo gênero.

\section{Definindo os gêneros do discurso}

Os gêneros podem ser definidos como o componente sócio-histórico das produções discursivas. Reportando-se a Bakhtin (2003), observa Filliettaz (2006, p. 75): "os discursos não emergem do nada e não fazem o objeto de uma (re)invenção perpétua, mas repousam sobre gêneros e modelos intertextuais sócio-historicamente constituídos". Nesse sentido, os gêneros dizem respeito a conhecimentos compartilhados pelos membros de uma coletividade, conhecimentos que atuam como os princípios organizacionais que regem uma atividade social intersubjetiva reconhecida (FILLIETTAZ, 2000, CUNHA, 2014).

No que se refere ao gênero reportagem impressa, a representação que o define deve se compor de propriedades típicas do mundo em que as reportagens se inserem. Dessa forma, toda reportagem impressa tem um autor e um leitor. Essas instâncias agentivas assumem, respectivamente, os status sociais institucionalmente definidos de jornalista e de cidadão².

A participação desses agentes em uma dada atividade (produzir/ler uma reportagem) se justifica por meio de finalidades ou visadas específicas (CHARAUDEAU, 2004). Enquanto o jornalista busca informar e captar o leitor, bem como satisfazer suas exigências de credibilidade e de atualidade, o leitor busca informar-se, consumir um produto comercial e validar suas exigências de credibilidade e de atualidade (CHARAUDEAU, 2006; CUNHA, 2009, 2010).

$\mathrm{Na}$ atividade que define a reportagem, opera-se ainda uma seleção dos conteúdos comumente mobilizados pelos agentes. Esses conteúdos são mais ou menos estáveis e costumam ser indicados pelas diferentes rubricas ou cadernos de um jornal ou revista: política, cotidiano, esporte, cultura, etc (CHARAUDEAU, 2006). Além disso, a veiculação de qualquer 
reportagem impressa está associada a um suporte, ou seja, a um local físico de fixação e circulação da produção discursiva (jornal, revista) (MARCUSCHI, 2003), que tem uma materialidade interacional característica e uma data de publicação.

Reunindo todos esses elementos, a representação referencial do gênero reportagem pode ser esquematizada com o auxílio da figura 1 .

Figura 1 - Representação referencial do gênero reportagem

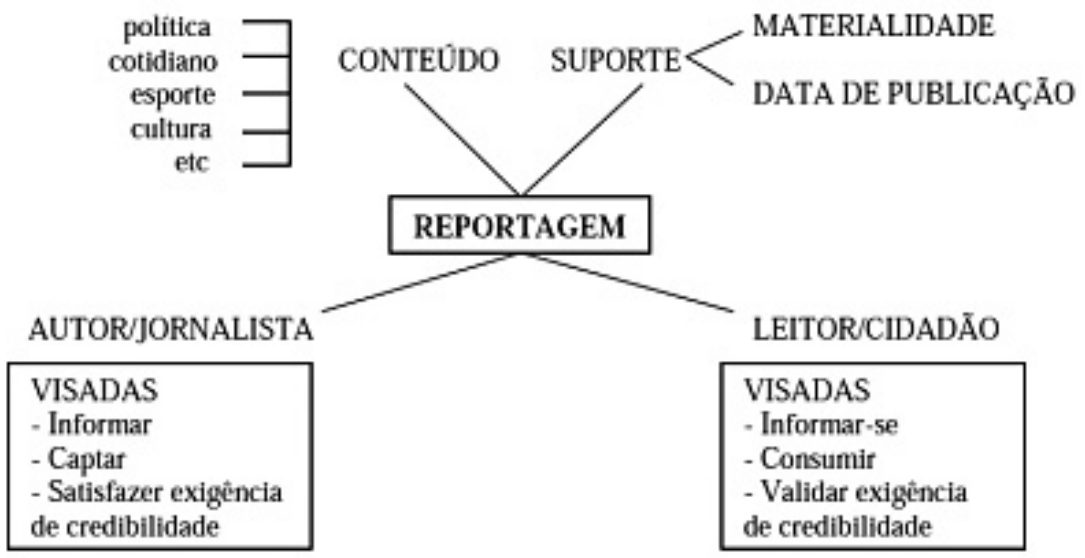

Tal como definida, essa representação genérica da reportagem deve ser entendida como o produto sócio-histórico de condutas sociais efetivas e, por isso, forma um feixe de conhecimentos com o qual é possível definir o gênero reportagem.

Como veremos a seguir, a representação genérica tem impacto sobre a constituição do mundo representado nos tipos de discurso. Especificamente, a representação de um gênero influencia a constituição dos tipos, porque cria expectativas quanto às propriedades referenciais que esperamos encontrar nas sequências em que os tipos se atualizam. 
O método utilizado por Adam (1992) para obter o protótipo narrativo consiste em, tomando a realidade cognitiva desse protótipo como um pressuposto, reunir em uma definição única observações de diferentes estudiosos, pertencentes a correntes teóricas muitas vezes incompatíveis, como nota Bronckart (2007), sobre narrativas produzidas em gêneros diversos, mas sobretudo literários. Obtido o protótipo dessa forma, parte o autor para a verificação do grau de semelhança de sequências particulares com esse protótipo. Esse método deriva do pressuposto, subjacente à Linguística Textual de Adam, de que as regularidades textuais poderiam ser estudadas desconsiderando-se o impacto do contexto de produção dos discursos sobre essas mesmas regularidades.

4 Para um aprofundamento na caracterização de cada episódio, bem como na metodologia empregada para a identificação do tipo narrativo e das sequências narrativas, ver Cunha (2013, cap. 4 e 5).
O impacto do gênero do discurso sobre a constituição dos tipos de discurso

Como vimos, o gênero se refere a uma representação referencial ou a um conjunto de conhecimentos esquemáticos relativos ao mundo em que o discurso se insere. Diferentes estudos apontam para o impacto do gênero sobre o mundo representado no discurso e sobre os recursos textual-discursivos empregados em sua representação, evidenciando que "os gêneros têm uma identidade e eles são entidades poderosas que, na produção textual, nos condicionam a escolhas que não podem ser totalmente livres nem aleatórias, seja sob o ponto de vista do léxico, grau de formalidade ou natureza dos temas" (MARCUSCHI, 2008, p. 156).

Sendo assim, é necessário investigar o impacto da representação genérica sobre as representações referenciais que definem os tipos de discurso. Em outros termos, a definição de um tipo de discurso deve resultar da percepção do impacto do mundo em que o discurso se insere (gênero do discurso) sobre o mundo que o discurso representa (tipo de discurso). Afinal, "o sub-domínio da vida social na qual a interação acontece opera uma seleção de recursos psicológicos, mobilizados pelos agentes que nela se encontram engajados" (ROULET; FILLIETTAZ; GROBET, 2001, p. 130). Nessa perspectiva, o gênero reportagem influencia a constituição do tipo narrativo desse gênero.

A seguir, apresento o tipo narrativo da reportagem, expondo a definição de cada um dos episódios que o constituem. A caracterização de cada episódio, detalhadamente exposta em Cunha (2013, cap. 5), se pautou na percepção de elementos recorrentes em um corpus de sequências narrativas. Esse corpus se constitui de 129 sequências extraídas de dezesseis reportagens publicadas em janeiro de 2010 nas revistas Carta Capital, Época, IstoÉ e Veja. Como decisões teóricas implicam consequências metodológicas, a elaboração do tipo narrativo da reportagem não ocorreu antes da identificação das sequências narrativas, como ocorre, por exemplo, em Adam (1992) 3 .

A identificação das recorrências caracterizadoras do tipo constituiu o resultado de constantes idas e vindas entre a elaboração dos episódios do tipo narrativo da reportagem e a análise das sequências narrativas ${ }^{4}$. 
Essa análise revelou que o tipo narrativo da reportagem diz respeito a uma representação referencial composta por seis episódios: sumário, estágio inicial, complicação, avaliação, resolução e estágio final.

Na parte inicial de 64 sequências narrativas do corpus, foi constatada a presença de um segmento discursivo em que o jornalista oferece indicações sobre o conteúdo de que trata a sequência narrativa. A recorrência de segmentos com essa característica me levou à proposição do episódio sumário. A leitura desse episódio motiva perguntas como estas: Como? Por quê? Como assim? Trata-se de indagações respondidas no restante da narrativa. Nesse sentido, o sumário parece constituir um recurso com o qual o jornalista, para captar o leitor e mantê-lo no processo da leitura, lança uma "isca", intrigando-o a respeito da relevância de acontecimentos que ele supostamente desconhece e que serão narrados nos episódios seguintes.

Em 98 sequências narrativas, há um segmento em que o jornalista oferece as coordenadas temporais e/ou espaciais dos acontecimentos tratados na sequência ou fornece informações que contextualizam esses acontecimentos. A presença desses segmentos em sequências narrativas de reportagens impressas parece se dever à busca do jornalista por atender à exigência de credibilidade do leitor, que, para crer na veracidade do que lhe é informado, precisa de informações acerca do momento e do local dos acontecimentos, bem como das circunstâncias que motivaram sua emergência (CHARAUDEAU 2006). Esses segmentos reforçam o efeito de objetividade buscado pelo uso de fotografias, que, compondo a reportagem, "mostram" o momento e o local dos acontecimentos, comprovando sua existência para o leitor. Nesse sentido, esses segmentos que reúno sob o conceito de estágio inicial, se diferenciam da situação inicial, proposta, por exemplo, por Adam (1992, 2011).

Para esse autor, a situação inicial "é uma forma de orientação ou de exposição narrativa que descreve o estado inicial do mundo dos personagens e suas relações. Ela coloca os elementos constitutivos do 'mundo' da história narrada" (ADAM 2011, p. 76). Essa definição é fortemente ancorada nos estudos literários e, particularmente, em Tomachévski (1965[1925], p. 274), que assim define esse episódio: “A narrativa das circuns- 
tâncias que determinam o estado inicial dos personagens e de suas relações se chama a exposição". Ao generalizar para as narrativas de modo geral constatações feitas quase um século antes sobre as narrativas literárias, Adam demonstra desconsiderar que a forma como o produtor de uma sequência narrativa apresenta o "mundo" dos personagens éinfluenciada pelo gênero a que pertence o texto em que a sequência ocorre.

Assim, na reportagem, o jornalista, por meio do estágio inicial, não busca apresentar o mundo dos personagens, como ocorre nos exemplos literários que ilustram a proposta de Adam, mas sim mostrar para o leitor que a sequência aborda acontecimentos verídicos e recentemente ocorridos, que se passaram em um local definido e que são a consequência de acontecimentos anteriores.

Ao tratar da forma como as mídias de modo geral selecionam os acontecimentos, observa Charaudeau (2006, p. 101): "Sendo a finalidade da informação midiática a de relatar o que ocorreu no espaço público, o acontecimento será selecionado e construído em função de seu potencial de 'atualidade', de 'socialidade' e de 'imprevisibilidade'". Nas análises, verificou-se que as sequências narrativas refletem, na concisão de sua estrutura, esse princípio geral, ao trazerem sempre um segmento que, de alguma forma, contribui para reforçar o potencial de atualidade, de socialidade e de imprevisibilidade dos acontecimentos centrais da reportagem.

De fato, em todas as sequências narrativas, há um segmento cuja temática desenvolve as informações expressas no subtítulo da reportagem e/ou no sumário da sequência narrativa, quando esse episódio é apresentado. Nesse segmento, o jornalista tematiza acontecimentos centrais que motivaram a própria escrita da reportagem e em relação aos quais os demais episódios indicam um antes e um depois, apresentam esclarecimentos e justificativas ou expressam uma postura avaliativa por parte de alguma instância enunciativa. A recorrência de segmentos com essas características me levou a propor um episódio que denomino complicação.

Vale esclarecer que a complicação do tipo narrativo da reportagem se difere da do tipo narrativo do relato de experiência pessoal estudado por Labov (1972), já que, como nesses relatos 
o locutor narrava uma situação em que correu risco de vida, era indispensável que a complicação expressasse acontecimento singular e inédito, digno de ser narrado. Portanto, ao contrário do que ocorre na complicação do gênero reportagem, a complicação do gênero relato de experiência pessoal não precisa ser recente e afetar a coletividade, bastando ser imprevisível.

Em 85 sequências narrativas, foram identificados segmentos em que o jornalista ou um personagem do mundo representado avalia acontecimentos expressos em outros episódios. Nesses segmentos, que reúno sob o episódio avaliação, é possível responsabilizar uma instância enunciativa por um ponto de vista acerca da informação expressa em quaisquer outros episódios do tipo narrativo, com exceção do sumário, que, talvez por apresentar uma natureza avaliativa, não foi objeto de avaliação em nenhuma sequência do corpus.

A incorporação desse episódio ao tipo narrativo da reportagem busca dar conta do fato de que, muitas vezes, o jornalista suspende a narração dos acontecimentos para apresentar uma avaliação desses mesmos acontecimentos, revelando por que eles devem ser interpretados como sendo interessantes, surpreendentes, preocupantes, absurdos, graves, importantes, etc.

$\mathrm{Na}$ análise, foi possível separar em dois tipos maiores as avaliações identificadas. De um lado, estão aquelas cuja responsabilidade enunciativa recai sobre o jornalista. Ou seja, nesse caso, é o próprio jornalista quem faz a avaliação. De outro lado, agrupam-se as avaliações cujos responsáveis são personagens do mundo representado. Nessas, o jornalista encena personagens realizando avaliações.

Em 91 sequências do corpus, o jornalista trata do resultado do acontecimento expresso na complicação, indicando que esse acontecimento deu origem a outros e satisfazendo a necessidade do leitor/cidadão de ser informado de toda a cadeia de acontecimentos cujo cerne é a complicação. A recorrência dos segmentos que expressam esses outros acontecimentos levou à proposição do episódio resolução.

Fortemente atrelada às propriedades do gênero reportagem, a resolução que proponho se diferencia do desenlace de Adam $(1992,2011)$ e do resultado de Labov (1972). Em ambos os 
estudiosos, a definição desse episódio é sucinta demais e não parece se articular ao gênero do discurso que lhe dá origem. Em Adam (2011, p. 77), o desenlace é rapidamente definido como o episódio que "permite à sequência se acabar". Em Labov (1972, p. 370), o resultado é o episódio que apenas responde à pergunta: "o que finalmente aconteceu?"

A resolução que proponho nasce da vontade do leitor/ cidadão de querer (e dever) saber o que se passa no espaço público. Por esse motivo, o jornalista, que tem a necessidade (e o dever) de informar, costuma narrar os acontecimentos decorrentes da complicação. Porque esses acontecimentos são importantes ou inesperados, a ponto de serem informados na complicação, eles criam no leitor a expectativa de uma continuação, relativa ao seu impacto na sociedade de modo geral ou na localidade onde se produziram. O episódio resolução do tipo narrativo da reportagem tem exatamente a função de permitir ao jornalista satisfazer essa expectativa do leitor.

Em 38 sequências narrativas do corpus, o jornalista traz um segmento que apresenta o momento final dos acontecimentos expressos na sequência. Diferentemente da situação final de narratólogos que estudaram gêneros literários, nas sequências narrativas de reportagens, os segmentos que apresentam o momento final não têm como finalidade expressar uma nova situação de equilíbrio em que os personagens, após as peripécias do enlace e do desenlace, se encontram em um estado diferente daquele em que estavam na situação inicial.

Na reportagem, esses segmentos indicam as ações ou as situações que estão mais próximas do momento da enunciação (a publicação da reportagem). Nesse sentido, eles têm como função indicar que os acontecimentos expressos ao longo da sequência narrativa resultaram em um estado ou em uma ação final que, ainda agora, no momento em que a reportagem é publicada, tem relevância para o leitor/cidadão e pode, de alguma forma, interferir em suas atitudes. Com base nesses segmentos, proponho a incorporação ao tipo narrativo da reportagem do episódio estágio final. 
Esses episódios podem ser agrupados na seguinte representação referencial do tipo narrativo da reportagem:

Figura 2 - O tipo narrativo da reportagem

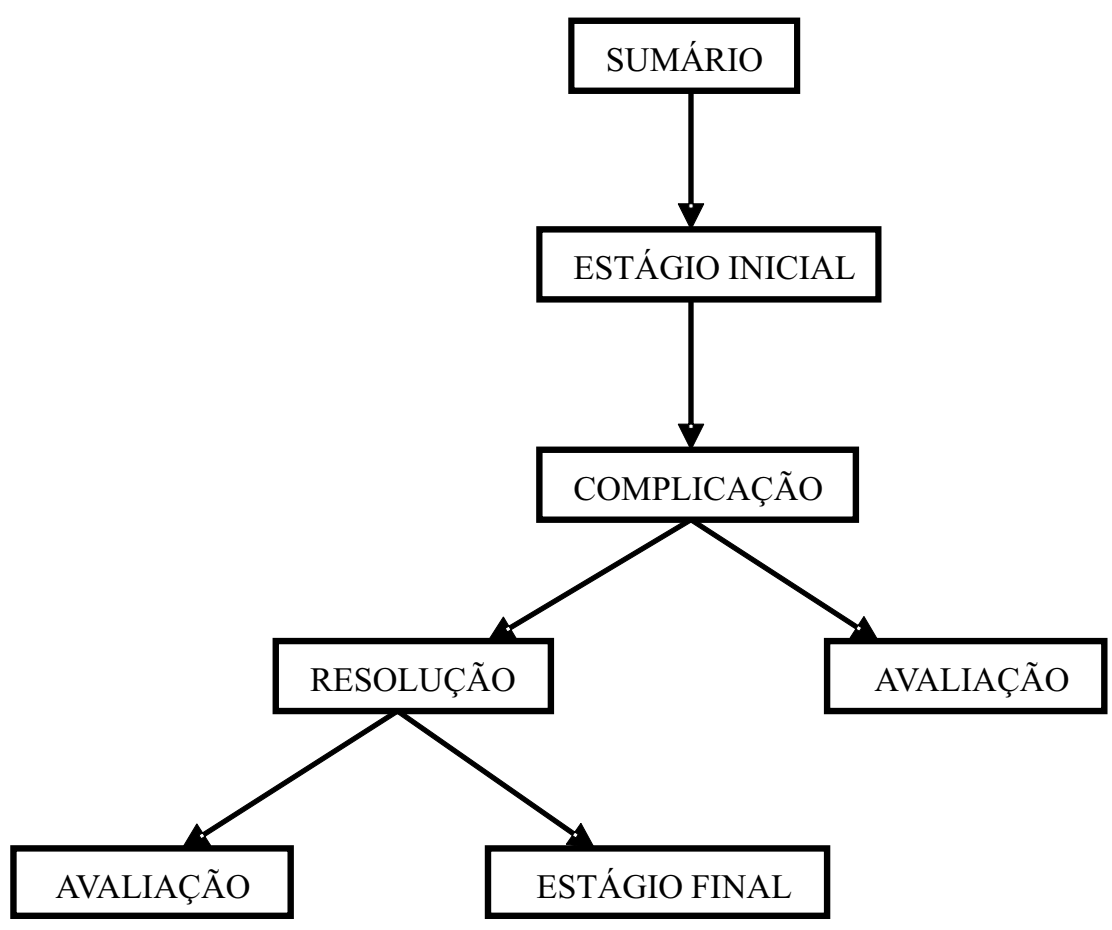

Diferentemente dos protótipos sequenciais de Adam (1992), essa representação não tem um caráter prototípico universal, uma vez que não subjaz às sequências narrativas produzidas no quadro de quaisquer gêneros do discurso. Dito de outra forma, essa representação não é transversal em relação aos gêneros, pois busca dar conta da produção e da interpretação das sequências narrativas pertencentes apenas a reportagens e, portanto, está profundamente atrelada às visadas e às instâncias enunciativas desse gênero. Além disso, como ela é elaborada a partir de um corpus de sequências narrativas extraídas de reportagens publicadas em janeiro de 2010, essa representação, assim como o gênero a que se subordina, é um construto profundamente sócio-histórico, não sendo válida para estudar, por exemplo, as sequências narrativas de reportagens publicadas há um século. 
Nesse sentido, ela deve ser compreendida como um recurso referencial de que lançamos mão sempre que precisamos produzir ou interpretar os segmentos narrativos de uma reportagem e não se aplica, portanto, à análise de sequências narrativas encontradas em exemplares de outros gêneros ou em reportagens produzidas em outros momentos históricos.

Por ser menos geral e não pretender dar conta das sequências narrativas produzidas no interior de todo e qualquer gênero, essa representação tem pelo menos duas vantagens: em primeiro lugar, possibilita uma análise mais sensível às especificidades de um dado gênero. Isso porque ela decorre das visadas, dos papéis sociais, do suporte e das condutas típicas associados ao gênero reportagem e, por isso, busca definir de forma mais realista as etapas envolvidas na produção de sequências desse gênero. No protótipo narrativo de Adam, os papéis sociais que os agentes assumem tipicamente e as finalidades típicas que procuram alcançar não têm qualquer relevância para a constituição dos tipos de discurso. Essa maneira de conceber os tipos promove uma dissociação inadequada entre as noções de gênero e tipo.

Em segundo lugar, como a elaboração dessa representação é fruto da análise das recorrências verificadas em um corpus de sequências narrativas de reportagens, ela permite extrair as particularidades de uma sequência narrativa jornalística, mesmo que essa sequência se afaste do modelo prototípico das sequências narrativas literárias. Como o protótipo de Adam é elaborado com base, principalmente, em narrativas literárias, as sequências que não apresentam suas características (qualidades) básicas simplesmente não são consideradas como narrativas ou são qualificadas como narrativas problemáticas ou defeituosas. Uma representação como a que proponho busca evitar esse viés prescritivo.

No próximo item, procuro esclarecer a terceira etapa da abordagem proposta neste trabalho. Definidos os tipos de um gênero com base na recorrência de elementos encontrados em um corpus de sequências discursivas, é possível, na terceira e última etapa, utilizar os tipos assim elaborados para identificar novas sequências discursivas presentes em outras produções pertencentes ao mesmo gênero. No item a seguir, veremos como o tipo narrativo da reportagem, elaborado neste item, 
pode ser empregado na percepção de que um segmento de uma reportagem pertence a esse tipo.

\section{O emprego dos tipos de discurso na identificação das sequências discursivas}

Assim como propõem Roulet, Filliettaz e Grobet (2001), esta abordagem considera que os tipos de discurso devem funcionar como instrumentos de análise que permitem extrair as sequências discursivas. Dessa forma, estabeleço, aproximando-me dos autores mencionados, uma distinção entre tipo de discurso e sequência discursiva. Enquanto o primeiro termo diz respeito a uma representação referencial típica que define como se narra, argumenta ou descreve em dado gênero, as sequências constituem segmentos discursivos empíricos em que os tipos se realizam ou se manifestam.

Neste trabalho, venho defendendo que os tipos são profundamente atrelados aos gêneros. Como consequência dessa imbricação das noções de gênero e tipo, é possível levar em consideração, no estudo das sequências de uma produção discursiva, elementos extralinguísticos ligados aos gêneros que, de modo geral, costumam ser negligenciados ou subestimados pelas abordagens que se guiam pela hipótese da universalidade e atemporalidade dos tipos.

Para mostrar o alcance desta proposta que retira sua singularidade da profunda integração entre os gêneros e os tipos, proponho uma análise deste segmento extraído de uma reportagem ${ }^{5}$ :

\section{Mar de lama}

Em 1998, mineiros e capixabas se animaram com o início da construção da BR-342, que ligaria o norte do Espírito Santo a Minas Gerais. Para pavimentar os 106 quilômetros da rodovia, foram celebrados três contratos com duas empreiteiras. Nos três o TCU encontrou sobrepreço - sempre na casa de $50 \%$ do valor global. Além disso, parte dos serviços que as empreiteiras alegam ter executado não foi fiscalizada pelo

Esse segmento faz parte da reportagem "Desvios subterrâneos", a qual foi publicada na revista Veja de 06/01/2010 e integra o corpus da pesquisa apresentada em Cunha (2013). governo. Por fim, o valor dos contratos aumentou sem nenhuma justificativa técnica. Uma estranheza atrás da outra. Como a obra se tornou um sorvedouro de dinheiro público, o TCU pediu sua paralisação. Hoje, há apenas 33 quilômetros asfaltados. Outros 27 quilômetros são transitáveis, mas ainda não receberam uma gota de asfalto. Nos 46 quilômetros restantes, a obra nem sequer foi iniciada. 
No plano referencial, o jornalista representa um mundo discursivo que é disjunto daquele em que ele e o leitor interagem ${ }^{6}$.

Inicialmente, o jornalista traz o sumário da sequência ("Mar de lama"), com o qual busca antecipar um aspecto do fato que será abordado. Como esse sumário traz poucas informações e remete tanto à lama das obras públicas quanto à "lama" da corrupção ligada a desvios de dinheiro público, ele parece ter como fim mais despertar a curiosidade do leitor do que facilitar a compreensão da sequência.

Depois, o jornalista informa, no estágio inicial, o local (BR-342, Espírito Santo, Minas Gerais) e o momento (1998) em que se produziram os acontecimentos, bem como parte das figuras reais do espaço público neles envolvidos (mineiros, capixabas, empreiteiras). Esses elementos temporais, espaciais e actoriais sinalizam, de modo explícito, que o jornalista trata de um mundo outro ou disjunto em relação ao mundo em que ele e o leitor interagem por meio da reportagem.

Após o estágio inicial, o jornalista informa, na complicação, os fatos que motivaram a escrita da sequência narrativa e que foram sumarizados no título (irregularidades na pavimentação da rodovia). Esses fatos têm o potencial de chamar a atenção do leitor/cidadão porque dizem respeito ao uso irregular do dinheiro público e, por isso, afetam uma grande parcela da população: os contribuintes.

Apresentados os acontecimentos, o jornalista, na avaliação, comenta a complicação, evidenciando que para ele as irregularidades encontradas no TCU são "uma estranheza atrás da outra". O jornalista emite uma avaliação negativa sobre as irregularidades, avaliação que pode ser compartilhada pelo leitor, já que este, ao interagir com o jornalista, assume o status social de cidadão.

Feita a avaliação, o jornalista informa ao leitor, na resolução, o resultado da complicação. Uma vez descobertas as irregula-

6 Segundo Bronckart (2007) e Filliettaz (1999), a disjunção entre o mundo que o discurso representa e o mundo em que o discurso se insere é própria da narratividade. ridades, a paralisação das obras foi um resultado previsto. Ao informar esse resultado, o jornalista atende à expectativa do leitor de que este, por assumir o status de cidadão, será informado da consequência da descoberta de irregularidades em obras públicas. 
Por fim, o jornalista apresenta, no estágio final, o estado resultante da resolução, informando ao cidadão como a rodovia está hoje (data da publicação da reportagem), depois da paralisação das obras.

Como evidencia a análise, o mundo representado no segmento constitui uma atualização do tipo narrativo da reportagem, o que revela que esse segmento é uma sequência narrativa. Esse mundo representado pode ser esquematizado por meio da seguinte estrutura referencial:

Figura 3 - Estrutura referencial

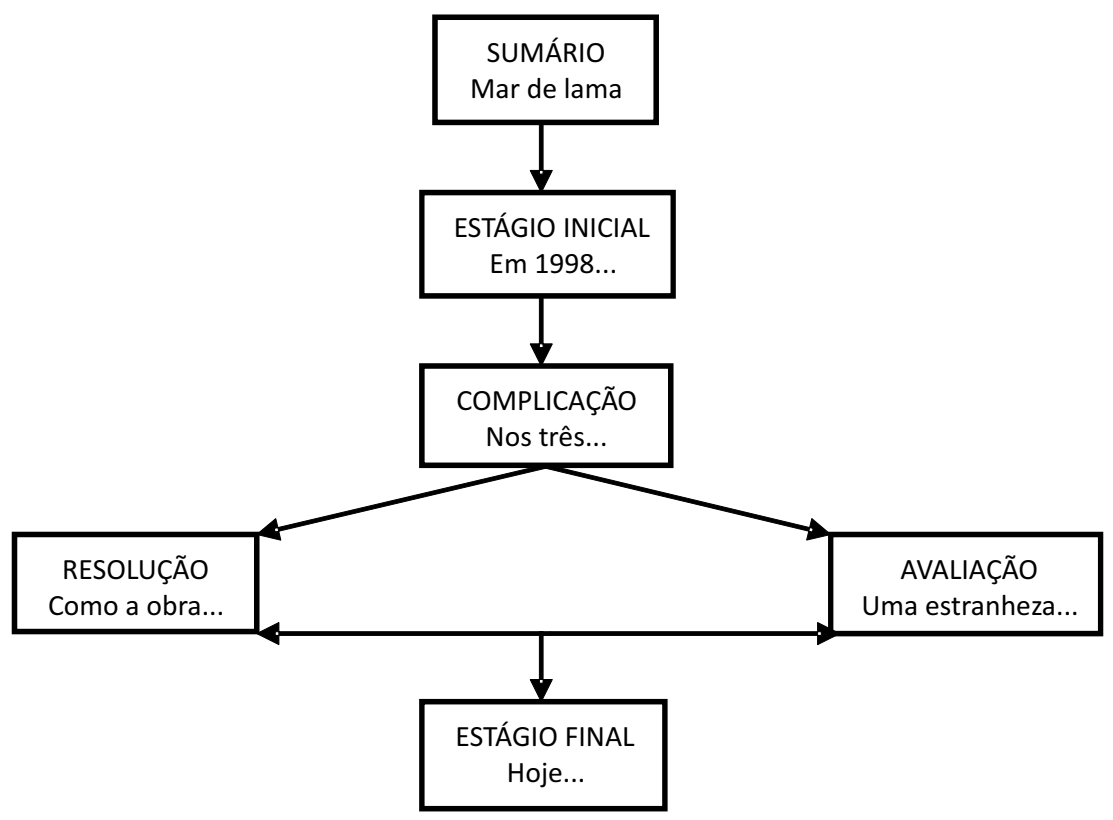

Ao contrário de uma análise estritamente sequencial, a análise empreendida considera os interactantes (autor e leitor), as ações que realizam, os status sociais que assumem na interação (jornalista e cidadão), bem como as visadas típicas do gênero reportagem. A consideração desses elementos só é possível porque, para a abordagem proposta, os gêneros têm impacto sobre a constituição de seus tipos. 


\section{Considerações finais}

Este trabalho propôs uma abordagem para o estudo da relação entre gêneros do discurso e tipos do discurso. Contrapondo-se à hipótese de que os tipos seriam universais, atemporais e transversais em relação aos gêneros, a abordagem parte da hipótese de que essas noções são de tal modo imbricadas que cada gênero possui tipos específicos.

Na abordagem apresentada, o tipo de discurso é concebido como uma representação referencial típica sobre o mundo do discurso, a qual é fortemente impactada pelo gênero do discurso ou pela representação referencial sobre o mundo em que o discurso se insere. Esse modo de conceber os tipos busca dar conta do fato de que eles são tão sócio-historicamente constituídos quanto os gêneros, cuja estrutura composicional integram.

Assim, o tipo narrativo da reportagem é diferente do tipo narrativo da fábula, por exemplo, já que jornalista e fabulista não mobilizam os mesmos recursos referenciais. Em outros termos, cada gênero define os episódios característicos do seu tipo narrativo, uma vez que em cada gênero há uma maneira característica de narrar. Dessa forma, ao longo do processo de constituição histórica do gênero fábula, a moral foi selecionada como um episódio do seu tipo narrativo. O mesmo não ocorreu com o gênero reportagem, cujas propriedades definidoras não selecionaram a moral, mas selecionaram, como vimos, o sumário como categoria típica de sua narrativa.

Com a abordagem delineada, a finalidade é, então, contribuir para uma melhor compreensão da relação entre os gêneros e os tipos, chamando a atenção para a inadequação de hipóteses teóricas, como a da universalidade dos tipos de discurso, que tem como consequência a desconsideração do papel dos gêneros sobre a constituição dos tipos. Ao desconsiderarem o papel dos gêneros sobre o modo como tipicamente narramos, descrevemos ou argumentamos, as abordagens que se guiam pela hipótese dessa universalidade estão impossibilitadas de oferecer uma compreensão mais adequada do fenômeno complexo que constitui a construção da estrutura composicional de um gênero. 
Nessas abordagens, quando a questão da influência do gênero sobre os tipos é tratada, faz-se referência apenas à dominância sequencial, ou seja, ao tipo de sequência (narrativo, descritivo, argumentativo) que predomina em um ou outro gênero ou à forma como as sequências tipicamente se articulam no nível global das produções discursivas pertencentes a um gênero. Não se explicam, portanto, as diferenças que intuitivamente reconhecemos no modo típico de narrar, descrever ou argumentar em diferentes gêneros.

Porque parte da hipótese de que cada gênero possui tipos específicos e, consequentemente, de que os tipos não são um conjunto limitado de entidades universais e transversais em relação a todos os gêneros, a abordagem apresentada constitui um ponto de partida interessante para se pensar em respostas para algumas questões:

- qual é o modo típico de descrever e argumentar no gênero reportagem?

- qual é o modo típico de narrar, descrever e argumentar em outros gêneros?

- como o modo típico de narrar, descrever e argumentar de um dado gênero se constituiu ao longo da história da formação desse gênero?

- quais as semelhanças e as diferenças entre os modos típicos de narrar, descrever e argumentar em diferentes gêneros?

- é possível utilizar o modo típico de narrar, descrever e argumentar de um gênero para narrar, descrever e argumentar em outro? Que efeitos de sentido esse tipo de empréstimo pode causar?

- quais implicações a hipótese de que cada gênero possui tipos específicos pode trazer para o processo de ensino e de aprendizagem dos gêneros e dos tipos?

- a hipótese de que cada gênero possui tipos específicos rejeita a ideia de que o aluno capaz de narrar segundo os moldes das narrativas literárias é capaz de narrar em qualquer gênero. Desse modo, como essa hipótese pode afetar as aulas e os materiais didáticos sobre os tipos de discurso? 
Essas questões são relevantes porque, ao serem respondidas, permitem elucidar aspectos ainda desconhecidos do funcionamento dos gêneros e dos tipos, bem como do modo como deles nos valemos para alcançar determinados fins em interações específicas. Além disso, permitem repensar, em novas bases, práticas pedagógicas cristalizadas e talvez ineficazes para a aprendizagem dos gêneros e do modo como neles se narra ou se argumenta.

Por permitirem a colocação dessa série de questões para os estudos do texto e do discurso, considero que a presente abordagem e a hipótese subjacente a todas as etapas de seu desenvolvimento abrem uma perspectiva bastante promissora para investigações futuras.

\section{REFERÊNCIAS}

ADAM, J. M. Les textes: types et prototypes. Paris: Nathan, 1992. . Genres de récits: narrativité et généricité des textes. Louvain-la-neuve: Academia L'Harmattan. 2011.

BAKHTIN, M. Os gêneros do discurso. In: BAKHTIN, M. Estética da criação verbal. São Paulo: Martins Fontes, p. 261-306, 2003.

BRONCKART, J. P. Atividade de linguagem textos e discursos: por um interacionismo sócio-discursivo. São Paulo: EDUC. 2007. BURGER, M. Identités de status, identités de role. Cahiers de linguistique française, v. 21, p. 35-59. 1999

. La gestion des activités: pratiques sociales, roles interactionnels et actes de discours. Cahiers de linguistique française, v. 26, p. 177-196. 2004.

CHARAUDEAU, P. Visadas discursivas, gêneros situacionais e construção textual. In: MACHADO, I. L.; MELLO, R. (Org.) Gêneros: reflexões em Análise do Discurso. Belo Horizonte: Núcleo de Análise do Discurso/Faculdade de Letras/UFMG, p. 13-41. 2004.

. Discurso das mídias. São Paulo: Contexto. 2006.

COUTINHO, M. A. Marcadores discursivos e tipos de discurso. Estudos Linguísticos. n. 2, p. 193-210. 2008. 
CUNHA, G. X. O impacto do contexto na construção da narrativa em uma reportagem do jornalismo político. In: NETO, F. K.; RUFINO, J. A.; BAPTISTA, M. R. (Org.) Espaços, sujeitos e sociedade: diálogos. Barbacena: EdUEMG, p. 81-95. 2009.

A atuação de sequências do tipo narrativo em um texto jornalístico impresso. Revista do GEL, v. 7, n. 1, p. 202-219, 2010.

A construção da narrativa em reportagens. 601f. Tese (Doutorado em Linguística) - Faculdade de Letras, Universidade Federal de Minas Gerais, Belo Horizonte, 2013.

. Para entender o funcionamento do discurso: uma abordagem modular da complexidade discursiva. Curitiba: Appris, 2014.

FILLIETTAZ, L. Une approche modulaire de l'hétérogénéité compositionnelle du discours: le cas des récits oraux. Cahiers de linguistique française, v. 21, p. 261-327. 1999.

Actions, activités et discours. 403f. Tese (Doutorado em Linguística) - Faculdade de Letras, Universidade de Genebra, Genebra. 2000.

La place du contexte dans une approche praxéologique $\mathrm{Du}$ discours. Le cas de l'argumentation dans les interactions scolaires. Pratiques, n.129-130, p. 71-88. 2006.

HERNANDES, N. A mídia e seus truques: o que jornal, revista, $\mathrm{TV}$, rádio e internet fazem para captar e manter a atenção do público. São Paulo: Contexto. 2006.

$\mathrm{LABOV}, \mathrm{W}$. The transformation of experience in narrative sintax. In: LABOV, W. Language in the inner city: studies in the black english vernacular. Philadelphia: University of Pennsylvania Press. 1972.

MAINGUENEAU, D. Elementos de linguística para o texto literário. São Paulo: Martins Fontes. 1996.

MARCUSCHI, L. A. A questão do suporte dos gêneros textuais. Língua, linguística e literatura. v. 1. n. 1, p. 09-40. 2003.

Gêneros textuais: definição e funcionalidade. In: DIONÍSIO, A. P.; MACHADO, A. R.; BEZERRA, M. A. (Org.) Gêneros textuais e ensino. Rio de Janeiro: Lucerna, p. 19-36. 2005. Produção textual, análise de gêneros e compreensão. São Paulo: Parábola Editorial. 2008. 
PESSOA, M. B. O gênero notícia no Brasil: notas para uma história. In: RAMOS, J. M.; ALKMIM, M. A. (orgs.) Para a história do português brasileiro: estudos sobre mudança lingüística e história social. v. 5. Belo Horizonte: Faculdade de Letras da UFMG, p. 545-578. 2007.

ROULET, E. Une description modulaire de l'organisation topicale d'un fragment d'entretien. Cahiers de linguistique française, v. 18, p. 11-32. 1996.

ROULET, E.; FILLIETTAZ, L.; GROBET, A. Un modèle et un instrument d'analyse de l'organisation du discours. Berne: Lang. 2001.

SCHNEUWLY, B. Gêneros e tipos de discurso: considerações psicológicas e ontogenéticas. In: SCHNEUWLY, B. et al. Gêneros orais e escritos na escola. Campinas: Mercado de Letras, p. 19-34. 2004.

SCHUTZ, A. Sens commun et interprétation scientifique de l'action humaine. In: . Le chercheur et le quotidien: phénoménologie des sciences sociales. Paris: Méridiens Klincksieck, p. 07-63. 1987.

TOMACHÉVSKY, B. Thématique. In: TODOROV, T. (Org.) Théorie de la littérature. Paris: Éditions du Seuil, p. 263-307. 1965[1925].

Van DIJK, T. Philosophy of action and theory of narrative. Poetics, v. 5: 287-332. 1976.

. Estruturas da notícia na imprensa. In: Van DIJK, T. Cognição, discurso e interação. São Paulo: Contexto, p. 122-156. 1992. WOLTON, D. Pensar a comunicação. Brasília: Editora Universidade de Brasília. 2004. 


\section{Abstract}

Toward a socio-historical approach of the relation between the concepts of discursive genre and discursive type

This paper presents an approach for the study of the relation between discursive genres and discursive types. This approach is supported by the hypothesis that each genre possesses specific types. To verify the validity and the reach of this hypothesis, this paper aims at showing, initially, that the theories that conceive the types and the sequences as universal standards (linguistics or cognitives) do not resist the analysis of a simple narrative sequence. After exposing the inconsistency of these theories, I propose, in a second moment, an approach that allows clarifying unknown aspects of the functioning of the genres and the way they can be used in order to reach specific objectives.

Key-words: discursive type; discursive genre; discursive approach. 